\title{
GRAPHICAL METHOD FOR DETERMINATION OF MQ-SERIES GAS SENSOR CIRCUIT PARAMETERS FOR A STAND-ALONE GAS ALARM SYSTEM
}

\author{
AJIBOYE, Aye Taiwo ${ }^{1 *}$; OPADIJI, Jaye Femi'; AJAYI, Adebimpe Ruth'; \\ ${ }^{1}$ University of Ilorin, Faculty of Engineering and Technology, Department of Computer Engineering. Nigeria. \\ * Corresponding author \\ e-mail: ajiboye.at@unilorin.edu.ng
}

Received 12 October 2021; received in revised form 19 November 2021; accepted 27 November 2021

\begin{abstract}
Background: MQ-series gas sensors belong to the metal oxide semiconductor (MOS) family of sensors that can sense the presence of many gases. These sensors find their application in gas alarm systems as key components. While necessary sensor circuit output voltage value for alarm point in a stand-alone gas alarm system is desirable, but what exact combination of the sensor circuit parameters is required? Hitherto, the determination of these circuit parameters has not been given much attention in the research community. Aim: the purpose of this work is to explore a structured graphical approach of determination of MQ series gas sensor circuit parameters for a stand-alone gas alarm system that yields desired sensor circuit output voltage value for the alarm point; the main objective of the study was to develop mathematical model equations that relate the: (i) sensor resistance (Rs) with the gas concentration ( $x$ ) and the sensor resistance at standard calibration concentration of the sensor base gas in the clean air ( $\left.R_{0}\right)$ and (ii) sensor circuit output voltage ( $\left.V_{R L}\right)$, load resistance $\left(R_{L}\right)$ and sensor resistance $(R s)$. It is expected from the model equations developed that graphical correlations of the sensor circuits parameters will be generated. Using these graphs for a particular case of an MQ-4 gas sensor under the influence of LPG, the parameters that yield desired sensor circuit output voltage of $2 \mathrm{~V}$ for $1000 \mathrm{ppm}$ of LPG alarm point will be determined. Methods: Model equations were developed for the sensor dynamics, and based on these model equations, graphs for the determination of required sensor parameters were plotted for a case of MQ-4 gas sensor response to LPG. Results and Discussion: The results yielded optimal values for $R_{O}, R_{S}$ and $R_{L}$ of $20 \mathrm{k} \Omega, 30 \mathrm{k} \Omega$ and $20 \mathrm{k} \Omega$ respectively, for alarm settings of $1000 \mathrm{ppm}$ and a desired sensor circuit output voltage of $2 \mathrm{~V}$. Based on determined parameters, the calibration equation for determination of best concentration value for a given value of emulated LPG concentration was developed. Using the method proposed in this study makes the process of determining the MQ-series gas sensor circuit parameters less cumbersome as their value can easily be obtained from the resulting graphs. Conclusions: a structured graphical approach for determination of MQ-series gas sensor circuit parameters for alarm points in a stand-alone gas alarm system showed that using MQ-4 gas sensor and LPG as the target gas, and for a sensor circuit output voltage of $2 \mathrm{~V}$ for alarm point at $1000 \mathrm{ppm}$ of LPG, the corresponding value of $\mathrm{R}_{O}, \mathrm{R}_{\mathrm{S}}$ and $\mathrm{R}_{\mathrm{L}}$ obtained were $20 \mathrm{k} \Omega, 30 \mathrm{k} \Omega$, and $20 \mathrm{k} \Omega$ respectively. Hence, a structured graphical approach is suitable for determining $M Q$ series gas sensor circuit parameters for a stand-alone gas alarm system under the influence of its associated gases.
\end{abstract}

Keywords: alarm point, base gas, calibration-concentration, gas concentration, gas sensor resistance

\section{INTRODUCTION:}

$M Q$-series gas sensors belong to the family of metal oxide semiconductor (MOS) gas sensors that can detect the presence of some volatile, oxidizable, or reducible gases in an oxygenated environment (Gómez, Pelegri-Sebastia and Lajara, 2020). This group of sensors has been found useful in food quality control (Peris and Escuder-Gilabert, 2009), hazardous gas detection (Chadry and Suryani, 2018), environmental monitoring (Capelli, Sironi and Del Rosso, 2014; Capelli and Sironi, 2017), medical treatment and diagnosis (Chen, Wang, and Choi, 2013) and electronic nose development (Górska-Horczyczak et al., 2016; Cui et al., 2019; Kanade and Shaligram, 2014). MQ-series gas sensors are commonly used in this regard owned to their high 
sensitivity, stability, and long life characteristics (Örnek and Karlik, 2012). The resistance of the active sensing layer of these sensors changes when in contact with the target gas. The relationship between the sensor resistance and gas concentration is non-linear (Liu et al., 2012) and depends on the gas type. When connected as one of the basic components in the sensor circuit, a certain voltage that depends on the type and concentration of the gas can be measured at the circuit output (Nayyar, Puri, and Le, 2016; Ponzoni et al., 2017).

The MQ-series gas sensors form the major component in many gas alarm systems due to their cost and sensitivity advantages. As reported by (Nnokwe, Ubochi, and Onwuzuruike, 2020) is a microcontroller-based gas leakage detection system that employs an MQ-6 gas sensor for sensing of LPG. This device monitors the concentration of leaked gas on a liquid crystal display (LCD) and sends messages to a user's mobile device as part of alarming conditions. Methane concentration measuring instrument was developed by (Harun and Sokku, 2019) using MQ135 and Arduino UNO as sensor and processor, respectively. The measured gas concentration is displayed on an LCD screen. An LPG leakage detection system in which MQ-2 was used as the sensor, LCD as the display, and the information regarding the gas leakage sent as SMS to the registered phone number via GSM module was presented by (Hasibuan and Idris, 2019). A combination of MQ-6 gas sensor and microprocessor was used by (Katrandzhiev and Karnobatev, 2016) as the main components to realize LPG concentration measuring device, which also produces audible sound and visible light as signs of alarm when there is gas leakage.

Developed by (Ahmed et al., 2018) is a microcontroller-based gas alarm system that triggers a buzzer and LED indicator when the alarm set point for the MQ-9 gas sensor was $37,000 \mathrm{ppm}$ of Methane gas. Designed by (Kumar and Kumari, 2019) are an Arduino-based system with MQ2, MQ4, and MQ135 gas sensors capable of monitoring the concentration of gases and also gives alarm when the concentration of the various types of gases in the atmosphere is above the threshold value and also sends a notification to designated mobile phones through SMS via GSM module. Present in (Munsadwala et al., 2019) is an loT-based hazardous gas identification, and visualization device is consisting of MQ07 and MQ135 for sensing the $\mathrm{CO}$ and $\mathrm{CO}_{2}$; and air quality, respectively. The sensors output was processed by Arduino microcontroller, and the output from the controller was sent to the cloud storage via loT infrastructure. An LPG leakage concentration detection, monitoring, and control system which employed MQ-6, Arduino microcontroller, LCD display, GSM module, buzzer, and relay DC motor for sensing, processing, visualizing the gas concentration, sending situation message to the registered phone number, producing audible sound and automatically controlled the stove gas release knob respectively was presented by (Soundarya et al., 2014).

A toxic and hazardous gas concentration detecting, measuring, and monitoring system using MQ-2 gas sensor, Arduino, and nRF24L01P Wireless Transceiver Module as a sensor, processor, and data transfer technology, respectively, was developed by (Mahbub, 2019). An Arduino-based embedded system for detecting toxic gas in the air was developed by (Holovatyy et al., 2018). This system monitors the gas concentration and triggers the alarm (Buzzer and red light) when the concentration is abnormal. The alarm message is sent as SMS to the registered phone number via the GSM module and displayed on the LCD and personal computer screen. Also developed by (Ibrahim, 2018) is a microcontrollerbased carbon monoxide and carbon dioxide detector using MQ-7 and MQ-135 for carbon monoxide and air quality sensing, respectively. The gas concentration was displayed in ppm on LCD, and the alarm is triggered when the threshold for the safe gas concentration is reached. The research conducted by (Jamal et al., 2019) focused on the development of a smart realtime monitoring instrument to detect and measure in addition to heat stress the toxic gases $\left(\mathrm{CO}, \mathrm{NO}_{2}\right.$, and $\mathrm{H}_{2} \mathrm{~S}$ ) concentration in ppm on Java developed Graphical User Interface (GUI) using the Internet of Things (IOT) technology. The designed system used MQ7, MQ136, and MQ131 gas sensors, Atmega 328-PU with its Wi-Fi shield 101 to sense, control, and Wi-Fi communication between Remote Terminal Unit and GUI.

Present by (Shahadat, Mallik, and Islam, 2019) is a system for monitoring LPG leakage and activation of alert that gives the buzzer sound, switching on specified relay(s), and sending an alert message to the administrator for the necessary actions. In this system, the gas leakage concentration is sensed by an MQ- 6 gas sensor whose output is fed to the microcontroller node for processing. When the reference threshold value is crossed, the controller switches on the relay(s) and buzzer(s), alerting the administrator via the loT server for necessary action. 
It was discovered from the consulted literature that majority of the gas alarm systems that employ MQ-series gas sensors as sensing elements, microcontrollers are normally used to interface the sensor(s) with the alarm unit. This is because additional functions like gas concentration monitoring, storage, displaying, and sending of data and information to remote terminals are required to be performed by the system. But suppose all the aforementioned additional functionalities are not required. In that case, a straightforward, simple, economical, and reliable stand-alone gas alarm system can be achieved by connecting the sensor circuit to the alarm output unit via a simple switching component like a transistor. To realize this type of stand-alone gas alarm system, a unique combination of sensor circuit parameters is required to achieve the required sensor circuit output voltage to activate the switching circuit that links the sensor circuit with the alarm output unit (buzzer or light source) at the alarm point. The alarm point is the value of gas concentration at which the alarm is expected to come on or a particular action to take place, and it is normally set for a given gas and sensor. However, determining the sensor circuit parameters to achieve the required sensor circuit output voltage for a given alarm point has not been well researched. Therefore, this study presents a structured graphical method for determining the sensor circuit parameter that yielded the needed sensor circuit output voltage for the alarm point.

To achieve the aim of this study, the mathematical model equations that relate the: (i) sensor resistance $\left(R_{S}\right)$ with the gas concentration $(x)$ and the sensor resistance at standard calibration concentration of the sensor base gas in the clean air $\left(R_{O}\right)$ and (ii) sensor circuit output voltage $\left(V_{R L}\right)$, load resistance $\left(R_{L}\right)$ and sensor resistance $\left(R_{S}\right)$ were developed. Based on these model equations, the graphs which relate the parameters together were plotted. Using these graphs for a particular case of an MQ-4 gas sensor under the influence of LPG, the parameters that yielded the desired sensor circuit output voltage of $2 \mathrm{~V}$ for $1000 \mathrm{ppm}$ of LPG alarm point were determined.

\section{MATERIALS AND METHODS:}

This section is devoted to developing mathematical relationships among the gas, sensor, and sensor circuit parameters. Also, based on the developed model equations, the graphs that summarize the effects of these parameters on one another were plotted. The desired circuit parameters value were then graphically determined from the plotted graphs.

\subsection{MQ-series Gas Sensor Model Equations}

The MQ-series gas sensor resistance, $R_{S}$ is related to other gas and sensor parameters, as shown in Equation (1) (Ajiboye et al., 2021).

$R_{S}=10^{\wedge}\left(m \log _{10} x+\log _{10} c+\log _{10} R_{O}\right)$

Where $m$ and $c$ are as defined in (Ajiboye et al., 2021.

Figure 1 shows the MQ-series gas sensor electrical equivalent circuit where $R_{H}$ the sensor heater resistance is. Based on Figure 1, the sensor output voltage is as expressed in Equation (2) where $V_{C C}$ is the supply voltage across the circuit.

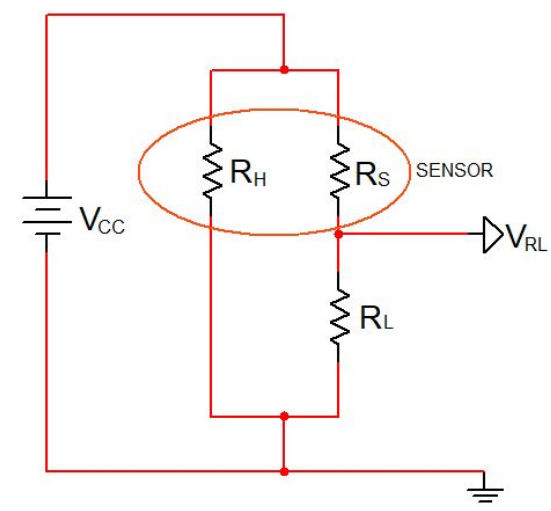

Figure 1. MQ-series gas sensor electrical equivalent circuit

$V_{R L}=\frac{R_{L} V_{C C}}{\left(10^{\left(m \log _{10} x+\log _{10} c+\log _{10} R_{O}\right)}+R_{L}\right)}$

From Equation (2), the concentration $(x)$ can be expressed as a function of other parameters and variables, as shown in Equation (3). 


\subsection{Determination of sensor circuit parameters}

The developed model equations were used to plot the graphs that relate the sensor and gas parameters together in this section. Using these graphs, the value of the parameter for the sensor circuit was determined.

\subsubsection{Determination of $R_{O}$}

The first parameter required for the characterization of the MQ-series gas sensor circuit is $R_{O}$. This parameter is normally determined using the experimental method because the value varies from sensor to sensor (Rumantri, Khakim, and Iskandar, 2018; Shahid et al., 2018). The variation is because keeping the sensor manufacturing condition constant is not practically achievable. Therefore variation in the resistance of the sensor under the same conditions of gas and environment is inevitable (Kim et al., 2006; Vandana et al., 2016). For easy understanding of the relationship among $\mathrm{R}_{\mathrm{S}}$, $\mathrm{x}$ and $R_{O}$ for the MQ-4 gas sensor considered in this study under the influence of its base gas $\left(\mathrm{CH}_{4}\right)$ the mesh plot of Figure 2 was carried out using Equation (1) for $10 \mathrm{k} \Omega \leq \mathrm{R}_{\mathrm{O}} \leq 60 \mathrm{k} \Omega$ and $200 \mathrm{ppm} \leq \mathrm{x} \leq 10000 \mathrm{ppm}$. The graph of Figure 3 which relate $R_{O}$ and $R_{S}$ when the sensor was assumed to be under the influence of the $\mathrm{CH}_{4}$ was extracted from Figure 2 when the concentration was $1000 \mathrm{ppm}$ of $\mathrm{CH}_{4}$ which is the base gas calibration concentration. Many types of Figure 3 can be gotten from Figure 2 at different concentrations, but the one considered in this study is for the analysis of the trend of $R_{S}$ as $R_{O}$ varies when the sensor is in the base gas at a calibration concentration of $1000 \mathrm{ppm}$.

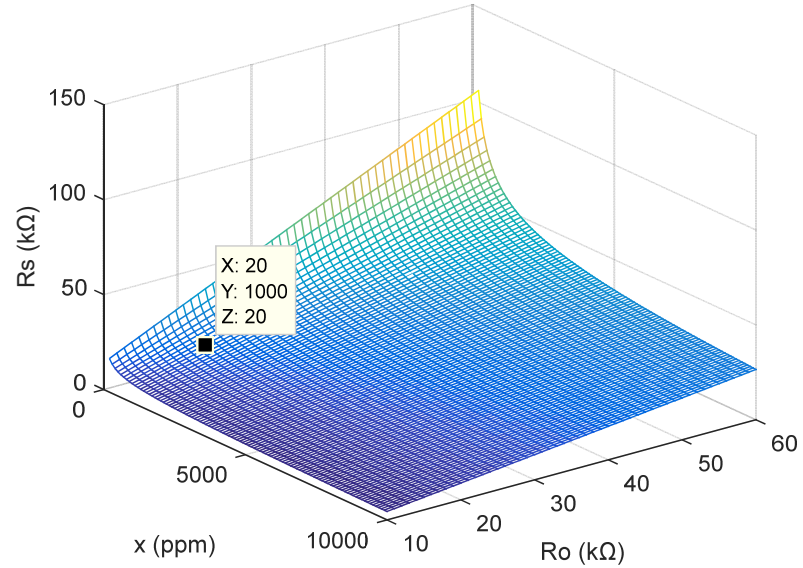

Figure 2. Mesh plot of $R_{S}$ versus $x$ and $R_{O}$ for MQ-4 gas sensor in the $\mathrm{CH}_{4}$

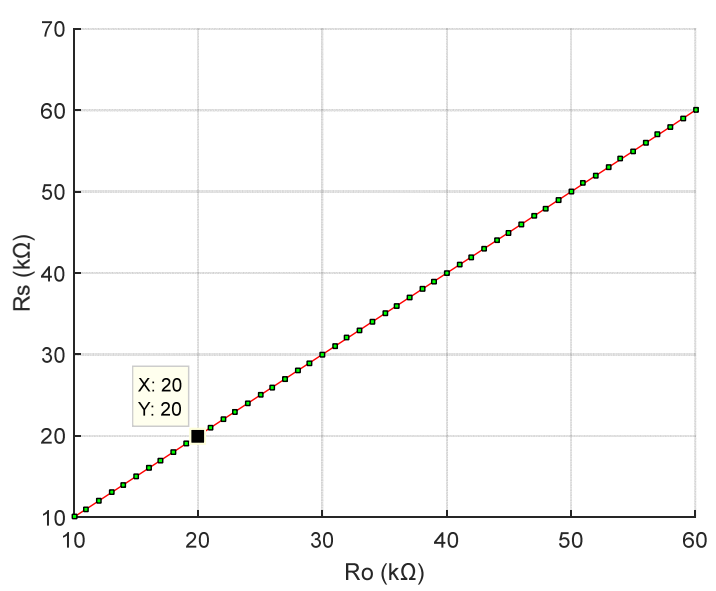

Figure 3. Plot of $R_{S}$ versus $R_{O}$ for $M Q-4$ sensor in the $\mathrm{CH}_{4}$ at a concentration of $1000 \mathrm{ppm}$

\subsubsection{Determination of $R_{S}$ in the gas under investigation}

For the purpose of this study, LPG was considered because of its domestic and industrial applications. Therefore, fixing of alarm point using MQ-4 gas sensor for LPG is presented. Based on Equation 1, Figure 4 is the mesh plot of $R_{0}, x$ and $\mathrm{R}_{\mathrm{S}}$ for MQ-4 gas sensor under the influence of LPG was obtained for $10 \mathrm{k} \Omega \leq R_{O} \leq 60 \mathrm{k} \Omega$ and $200 \mathrm{ppm} \leq x \leq 10000 \mathrm{ppm}$. $\mathrm{R}_{\mathrm{S}}$ can be determined from Figure 4 for a given value of $\mathrm{R}_{\mathrm{O}}$ and $x$. The alarm point is determined by the $\mathrm{x}$ value for a given gas. Since the gas under consideration in this study is LPG, a practical threshold value that human beings can withstand (1000 ppm) is used as the alarm point. Based on this concentration, the graph of Figure 5 which relate $R_{S}$ and $R_{O}$ was extracted from Figure 4 to show the relationship between these parameters when $\mathrm{x}=1000 \mathrm{ppm}$. It 
should be noted that at any given value of $x$ on the surface of Figure 4, the like of Figure 5 can be generated for a better understanding of the trend of the relationship between $R_{S}$ and $R_{O}$ for the concentration in question. The value of $R_{S}$ for any specified value of $R_{0}$ can easily be obtained from Figure 5.

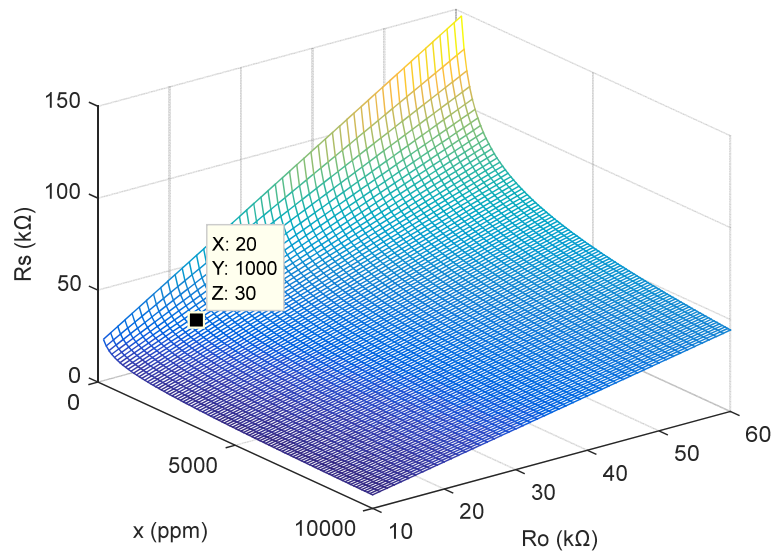

Figure 4. Mesh plot of $\mathrm{R}_{S}$ versus $\mathrm{x}$ and $\mathrm{R}_{S}$ for MQ-4 gas sensor in LPG

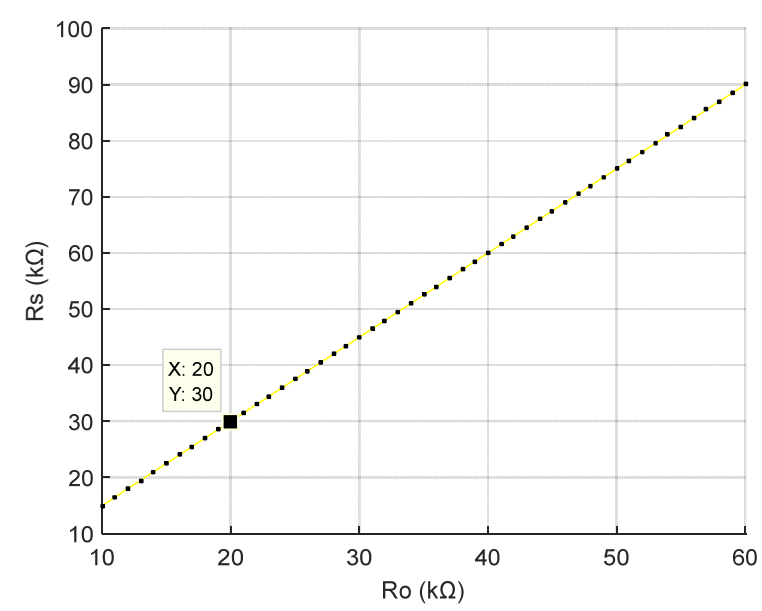

Figure 5. Plot of $R_{S}$ versus $R_{O}$ for $M Q-4$ gas sensor in LPG at concentrations of 1000 ppm

\subsubsection{Determination of the sensor circuit $R_{L}$ for alarm point}

Applying Equation 2, the relationship among $\mathrm{V}_{\mathrm{RL}}, \mathrm{R}_{\mathrm{O}}$ and $\mathrm{R}_{\mathrm{L}}$ is demonstrated in the mesh plot of Figure 6 for $10 \mathrm{k} \Omega \leq R_{O} \leq 60 \mathrm{k} \Omega$ and $10 \mathrm{k} \Omega \leq$ $R_{L} \leq 47 \mathrm{k} \Omega$. Figure 6 make the relationship among $V_{\mathrm{RL}}, \mathrm{R}_{\mathrm{S}}$ and $\mathrm{R}_{\mathrm{L}}$ comprehendible at a glance. For any given value of $R_{S}$ the relationship between $V_{R L}$ and $\mathrm{R}_{\mathrm{L}}$ can be established.

For the purpose of this study, it was assumed that $\mathrm{R}_{\mathrm{O}}=20 \mathrm{k} \Omega$, therefore, $\mathrm{R}_{\mathrm{S}}=30 \mathrm{k} \Omega$ as can easily be evaluated from Figure 5 . The graph that relates $V_{R L}$ and $R_{L}$ together was extracted from Figure 6 for clarity purpose and is as shown in Figure 7. Using Figure 7, the value of $\mathrm{R}_{\mathrm{L}}$ for any desired value of $\mathrm{V}_{\mathrm{RL}}$ for the sensor circuit can be determined.

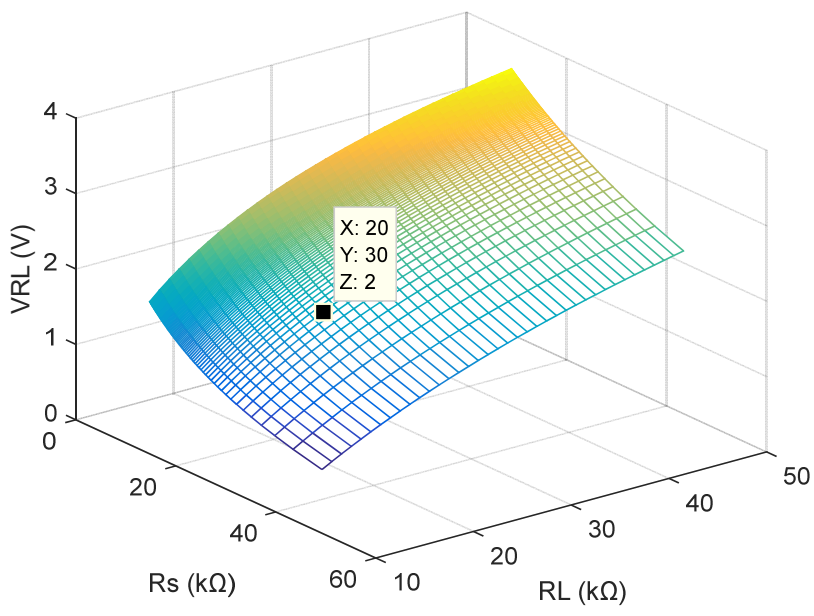

Figure 6. Mesh plot of $V_{R L}$ versus $R_{S}$ and $R_{L}$ for $M Q-4$ gas sensor in LPG

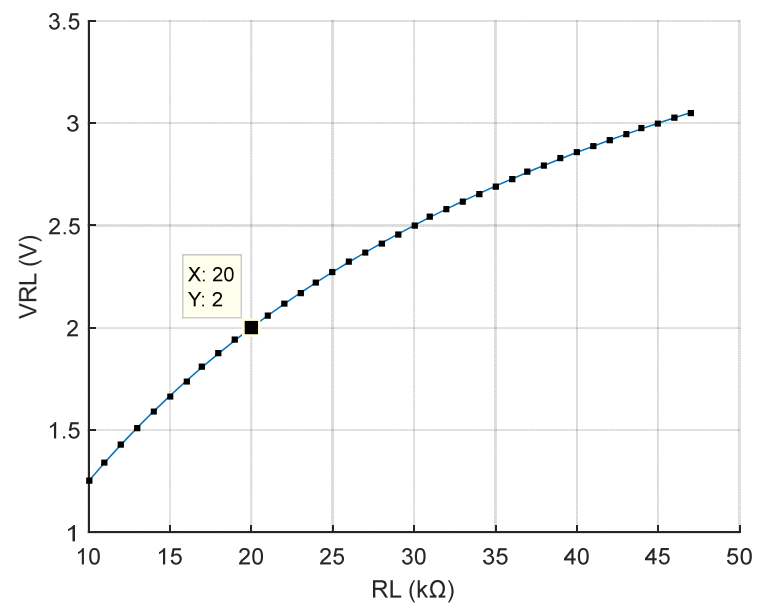

Figure 7. Plot of $V_{R L}$ versus $R_{L}$ for $M Q-4$ gas sensor in LPG

\subsection{Experimental Setup}

Using the determined sensor circuit parameters, the Arduino-based gas-alarm system shown in Figure 8 was developed and calibrated using simulation and emulation data. The simulation and emulation were carried out by 
applying Equation 3 and the experimental setup shown in Figure 9, respectively.

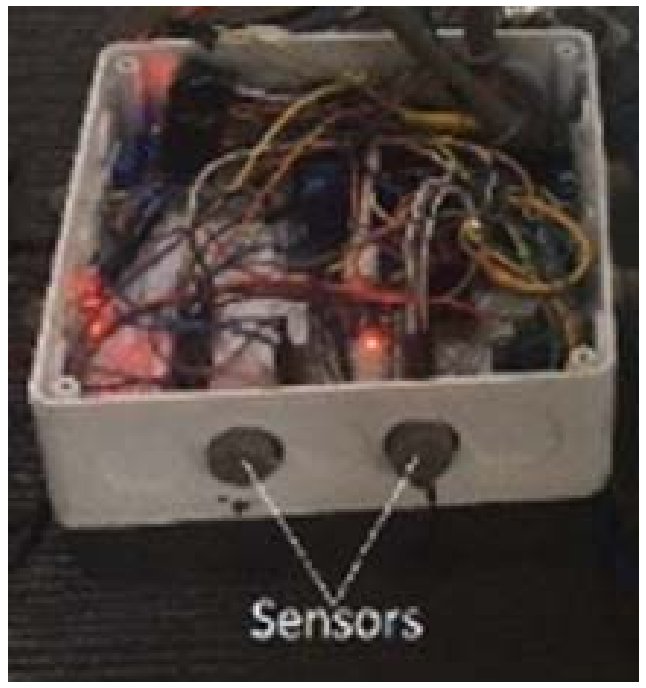

Figure 8. Developed Arduino-based gas-alarm system

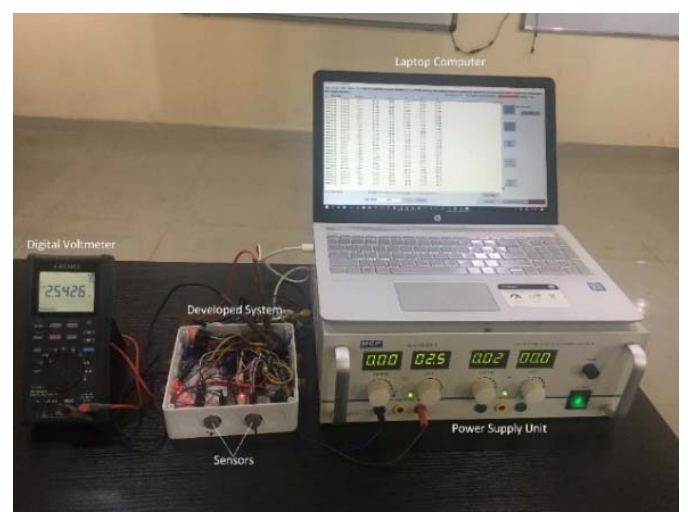

Figure 9. system emulation experimental setup

The setup consists of a digital meter for monitoring the sensor circuit emulated voltage, the developed system, a variable dc power supply unit for supplying the sensor circuit emulated voltage, and a laptop PC for monitoring and storage of system output (emulated concentration). The developed system was powered from an in-built $+5 \mathrm{~V}$ dc source, and the output of the variable power supply was connected to the input pin of the microcontroller to mimic the sensor circuit output voltage. Then the voltage from the variable power supply was varied within $1.545 \mathrm{~V}$ and $3.455 \mathrm{~V}$, which is the sensor circuit expected output voltage range when LPG concentration was in the range of 200 to $10000 \mathrm{ppm}$. The system output, LPG concentration levels were logged into the laptop $\mathrm{PC}$ as the input voltage to the microcontroller was varying.

\section{RESULTS AND DISCUSSION:}

The mesh plot of Figure 2 makes the presentation of the relationship among $\mathrm{R}_{\mathrm{S}}, \mathrm{x}$ and $\mathrm{R}_{\mathrm{O}}$ for MQ-4 gas sensor in $\mathrm{CH}_{4}$ to be compact. Also, the extraction of Figure 3 from Figure 2 for the demonstration of the relationship between $R_{S}$ and $\mathrm{R}_{\mathrm{O}}$ when $\mathrm{x}=1000 \mathrm{ppm}$ provides room for $\mathrm{a}$ better understanding of the relationship and makes the range of these parameters clearer. As can be seen from Figure 3 , the relationship between $R_{S}$ and $R_{O}$ is linear, which make it easy to determine $R_{S}$ for any given value of $R_{O}$ or vice versa. Since $\mathrm{R}_{\mathrm{O}}=20 \mathrm{k} \Omega$ when the sensor is assumed to be in $\mathrm{CH}_{4}$ at calibration concentration of $1000 \mathrm{ppm}$ in clean air, the value of $R_{S}$ is also $20 k \Omega$ as can be seen from Figure 3 .

To capture the relationship among $R_{S}$, $x$ and $R_{O}$ with easy when MQ-4 is in the vicinity of LPG, the mesh plot of Figure 4 was constructed. It can be seen from Figure 4 that at any spot on the mesh, the value of $\mathrm{R}_{\mathrm{S}}$ for any combination of $x$ and $\mathrm{R}_{\mathrm{O}}$ value can be determined. Furthermore, Figure 5 was extracted from Figure 4 to make a visualization of the relationship between $R_{S}$ and $\mathrm{R}_{\mathrm{O}}$ clearer. Figure 5 reveal that the relationship between $R_{S}$ and $R_{O}$ is linear. Therefore, the value of $R_{S}$ for a given value of $R_{O}$ can easily be determined from Figure 5, but $\mathrm{R}_{0}=20 \mathrm{k} \Omega$ for this study; therefore, from Figure 5, the corresponding value of $\mathrm{R}_{\mathrm{S}}$ is $30 \mathrm{k} \Omega$.

The relationship among $V_{R L}, R_{S}$ and $R_{L}$ was present in Figure 6. From this Figure, the circuit response to any combination of $R_{S}$ and $R_{L}$ within the specified range can be captured at a glance. Since the value of $R_{S}$ has been determined to be $30 \mathrm{k} \Omega$ using Figure 5 , this value of $\mathrm{R}_{\mathrm{S}}$ yielded Figure 7 from Figure 6. It can be seen from Figure 7 that $1.25 \mathrm{~V} \leq \mathrm{V}_{R L} \leq 3.05 \mathrm{~V}$ and $10 \mathrm{k} \Omega \leq R_{L} \leq$ $47 k \Omega$ and $V_{R L}$ bears a nonlinear relationship with $R_{L}$. Assuming the required sensor circuit voltage value of $2 \mathrm{~V}$, then the corresponding value of $\mathrm{R}_{\mathrm{L}}$ that can produce this voltage using Figure 7 will be $20 \mathrm{k} \Omega$.

The system calibration graph of Figure 10 was obtained by plotting the simulated (ideal) against emulated (assumed practical) LPG concentration data. 


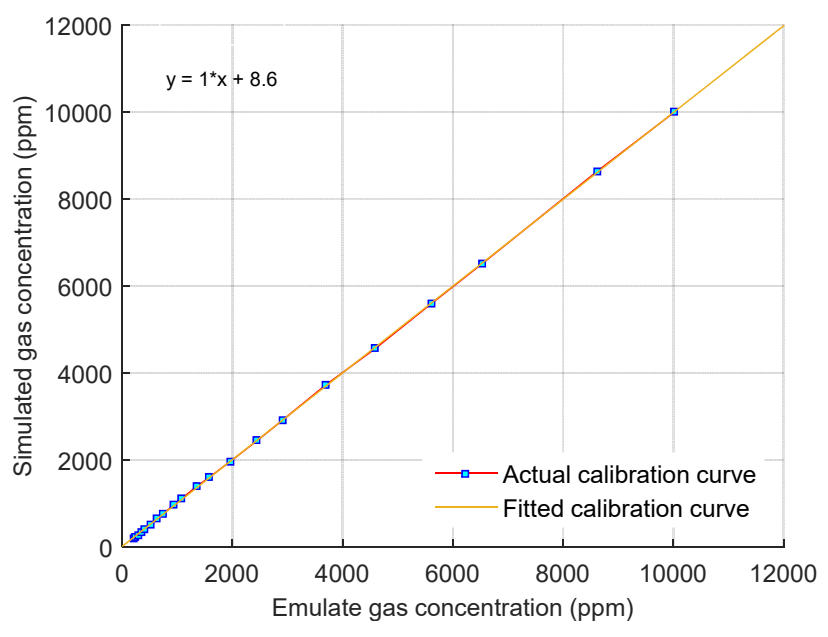

Figure 10. system calibration curve

Since the plot yielded a straight-line graph, the data were fitted linearly. The resulting system calibration equation that can be used to find the best concentration for a given value of emulated LPG concentration is shown in Equation (4), where $y$ and $x$ are the predicted and emulated LPG concentrations in ppm respectively.

$$
y=x+8.6
$$

At this stage, it can be seen that a structured graphical method for the determination of sensor circuit parameters, namely, $R_{S}, R_{O}$ and $R_{L}$ for alarm point, which is required for the proper functioning of MQ-series-based, a stand-alone gas alarm system has been developed and demonstrated.

\section{CONCLUSIONS:}

A structured graphical method for determining MQ-series gas sensor circuit parameters for alarm points in a stand-alone gas alarm system was developed and demonstrated using MQ-4 gas sensor and LPG as the target gas. The developed method is concise, straightforward forward and time-saving. The method is less prone to analytical error since all that is required is the proper visual reading of the parameter value from the graph. For a particular case of expected sensor circuit output voltage of $2 \mathrm{~V}$ for alarm point at $1000 \mathrm{ppm}$ of LPG, the corresponding value of $\mathrm{R}_{O}, \mathrm{R}_{\mathrm{S}}$ and $\mathrm{R}_{\mathrm{L}}$ obtained were $20 k \Omega, 30 k \Omega$, and $20 \mathrm{k} \Omega$ respectively. An Arduino-based stand-alone gas-alarm system was developed and calibrated using simulation and emulation LPG concentration data.

The method can be applied to any type of $M Q$-series gas sensor under the influence of its associated gases.

\section{DECLARATIONS}

\subsection{Study Limitations} study.

No limitations were known at the time of the

\subsection{Acknowledgements}

Not applicable.

\subsection{Funding source}

This research was funded by the authors.

\subsection{Competing Interests}

No conflict of interest exists in this publication.

\subsection{Open Access}

This article is licensed under a Creative Commons Attribution 4.0 (CC BY 4.0) International License, which permits use, sharing, adaptation, distribution, and reproduction in any medium or format, as long as you give appropriate credit to the original author(s) and the source, provide a link to the Creative Commons license, and indicate if changes were made. The images or other third-party material in this article are included in the article's Creative Commons license unless indicated otherwise in a credit line to the material. If material is not included in the article's Creative Commons license and your intended use is not permitted by statutory regulation or exceeds the permitted use, you will need to obtain permission directly from the copyright holder. To view a copy of this license, visit http://creativecommons.org/licenses/by/4.0/.

\section{REFERENCES:}

1. Ahmed, N. B., Tahsin, K. N., Khan, S., Hoq, M. and Alam, D. (2018). Design and implementation of a microcontroller based flammable gas detector and automatic alarm system to ensure the industrial and domestic safety. Asian Journal of Science and Technology, 9(1), 7425-7429.

2. Ajiboye, A., Opadiji, J., Yusuf, A. and 
Popoola, J. (2021). Analytical determination of load resistance value for MQ-series gas sensors: MQ-6 as case study.Telkomnika, 19(2), 575-582.

3. Capelli, L. and Sironi, S. (2017). Monitoring odour emisssions from an oil and gas plant: Electronic nose performance testing in the field. In 2017 ISOCS/IEEE International Symposium on Olfaction and Electronic Nose (ISOEN), 1-3.

4. Capelli, L., Sironi, S. and Del Rosso, R. (2014). Electronic noses for environmental monitoring applications. Sensors, 14(11), 19979-20007.

5. Chadry, R., and Suryani, A.I. (2018). Embedded System Using Field Programmable Gate Array (FPGA) myRIO and LabVIEW Programming to Obtain Data Patern Emission of Car Engine Combustion Categories. JOIV: International Journal on Informatics Visualization, 2(2), 56-62.

6. Chen, S., Wang, Y. and Choi, S. (2013). Applications and technology of electronic nose for clinical diagnosis.

7. Cui, S., Inocente, E. A. A., Acosta, N., Keener, H., Zhu, H., and Ling, P.P. (2019). Development of fast e-nose system for early-stage diagnosis of aphid-stressed tomato plants. Sensors, 19(16), 3480.

8. Gómez, J.C., Pelegri-Sebastia, J., and Lajara, R. (2020). Circuit Topologies for MOS-Type Gas Sensor. Electronics, 9(3), 525.

9. Górska-Horczyczak, E., Guzek, D., Molęda, Z., Wojtasik-Kalinowska, I., Brodowska, M. and Wierzbicka, A. (2016). Applications of electronic noses in meat analysis. Food Science and Technology, 36, 389-395.

10. H. Electronics, "Technical Data MQ-4 Gas Sensor," ed, p. 2.

11. Hanwei (2019). Technical Data MQ-6 Gas Sensor. E. H. Sensors, ed. China: Hanwei Sensors, Ed., ed, 1-2.

12. Harun, S. F. and Sokku, S. R. (2019). Measurement of Level Content of Methane in Household Waste Based on Arduino and Gas Sensor. Journal of Physics: Conference Series, 1244(1), 012042.

13. Hasibuan, M. S. and Idris, I. (2019) Intelligent LPG gas leak detection tool with SMS notification. Journal of Physics: Conference Series, 1424(1), 012020.

14. Holovatyy, A., Teslyuk, V., Lobur, M., Pobereyko, S. and Sokolovsky, Y. (2018). Development of arduino-based embedded system for detection of toxic gases in air. IEEE 13th International Scientific and Technical Conference on Computer Sciences and Information Technologies (CSIT), 1, 139-142.

15. Ibrahim, A. A. (2018) Carbon Dioxide and Carbon Monoxide Level Detector. 21st International Conference of Computer and Information Technology (ICCIT), 1-5.

16. Jamal, H., Huzaifa, M., Sodunke, M. A. and Odiete, J. O. (2019). Smart Heat Stress and Toxic Gases Monitoring Instrument with a Developed Graphical User Interface Using loT. International Conference on Electrical, Communication, and Computer Engineering (ICECCE), 1-6.

17. Kanade, A. and Shaligram, A. (2014). Development of an E-Nose using metal oxide semiconductor sensors for the classification of climacteric fruits. International Journal of Scientific and Engineering Research, 5(2).

18. Katrandzhiev, N. T. and Karnobatev, N. N. (2016). Elaboration of a Microprocessor Unit for Gas Measurement with Sensor MQ-6. Scientific Works of the University of Food Technologies, 63(2), 299 - 306.

19. Kim, J. Y., Kang, S. W., Shin, T. Z., Yang, M. K. and Lee, K. S. (2006). Design of a smart gas sensor system for room aircleaner of automobile-thick-film metal oxide semiconductor gas sensor. International Forum on Strategic Technology, 72-75.

20. Kumar, P. N. S. and Kumari, A. K. (2019). Design of Gas Detection and Monitoring System using loT. International Journal of Engineering Research and Technology (IJERT), 8, 463 - 468. 
21. Liu, X., Cheng, S., Liu, H. and Hu, S. (2012). Daqiang Zhang 2 and Huansheng Ning, a survey on gas sensing technology review. Sensors, 12(7), 9635-9665.

22. Mahbub, M. (2019). Toxic and hazardous gas detection, measurement, and monitoring system for safety assurance in home and industrial application of wireless sensor node. Engineering and Technology Research, 1, 089- 098.

23. Munsadwala, Y., Joshi, P., Patel, P. and Rana, K. (2019). Identification and visualization of hazardous gases using loT. 4th International Conference on Internet of Things: Smart Innovation and Usages (IOT-SIU), 1-6.

24. Nayyar, A., Puri, V. and Le, D.-N. (2016). $A$ comprehensive review of semiconductor-type gas sensors for environmental monitoring. Review of Computer Engineering Research, 3(3), 5564.

25. Nnokwe, C. C., Ubochi, B. C. and Onwuzuruike, K. V. (2020). Development of a Gas Leakage Detection System. Journal of Electrical Engineering, Electronics, Control, and Computer Science, 6(4), 23-28.

26. Örnek, Ö., and Karlik, B. (2012). An overview of metal oxide semiconducting sensors in electronic nose applications. in Proc. of the 3rd International Symposium on Sustainable Development, 2, 506-515.

27. Peris M., and Escuder-Gilabert, L., (2009). A 21st century technique for food control: Electronic noses. Analytica chimica acta, 638(1), 1-15.

28. Ponzoni, A., Baratto, C., Cattabiani, N., Falasconi, M., Galstyan, V. and NunezCarmona, E. Metal oxide gas sensors, a survey of selectivity issues addressed at the SENSOR Lab, Brescia (Italy). Sensors, 17(4), 714.

29. Rumantri, R., Khakim, M. and Iskandar, I. (2018). Design and characterization of lowcost sensors for air quality monitoring system. Jurnal Pendidikan IPA Indonesia, 7, 347-354.
30. Shahadat, M. M., Mallik, A. and Islam, M. (2019). Development of an automated gasleakage monitoring system with feedback and feedforward control by utilizing loT. Facta universitatis-series: Electronics and Energetics, 32(4), 615-631.

31. Shahid, A., Choi, J.-H., Rana, A. U. H. S. and Kim, H.S. (2018). Least squares neural network-based wireless E-Nose system using a $\mathrm{SnO}_{2}$ sensor array. Sensors, 18(5), 1446.

32. Soundarya, T., Anchitaalagammai, J., Deepa, P. and Karthick Kumar, S. (2014). C-leakage: Cylinder LPG Gas leakage Detection for home safety. IOSR Journal of Electronics and Communication (IOSRJECE), 9(1), 53-58.

33. Vandana, K., Baweja, C., Simmarpreet, and Chopra, S. (2016). Influence of Temperature and Humidity on the Output Resistance Ratio of the MQ-135 Sensor. Int. J. Adv. Res. Comput. Sci. Softw. Eng, 6(4), 423-429. 